\title{
IS THE TELEVISION LICENCE FEE FIT FOR PURPOSE IN THE DIGITAL ERA?
}

\author{
Helen Weeds*
}

\begin{abstract}
In the context of the UK's ongoing review of the BBC's Royal Charter, this article discusses the future of the television licence fee. As channels proliferate and new ways of watching television take hold, there is increasing pressure on the TV licence system. Drawing on an analysis of the rationale for public service broadcasting, the article considers whether the licence fee can be adapted to reflect this new world or should be replaced by a different funding model. It concludes that while modernising the TV licence fee to close the 'iPlayer loophole' would patch up the current system, it would be preferable to replace the licence fee altogether, perhaps with a household levy. Subscription may be a useful top-up for nonessential services where a broad reach is less important. The ban on the carrying of advertising by the BBC should also be reconsidered.
\end{abstract}

JEL codes: D62, H44, L38, L82, L88.

Keywords: BBC Charter review; public service broadcasting; TV licence.

\footnotetext{
${ }^{*}$ Lecturer in Economics, University of Essex, and Director, Multimedia Economics Ltd. Email: hfweeds@essex.ac.uk, helen@multimediaeconomics.com. An earlier version of this article was presented as a Beesley Lecture at the Institute of Directors on 8 October 2015. The author would like to thank especially Diane Coyle, discussant at the Beesley Lecture, and also Simon Anderson, Martin Peitz, Alan Sewell, Jon Stern, Damian Tambini, Mark Williams, Lorna Woods, Len Shackleton and three anonymous referees for helpful comments and discussion. The views expressed and any errors are entirely those of the author.
} 


\section{Introduction}

In the UK, the ten-year Royal Charter setting out the purposes and duties of the British Broadcasting Corporation (BBC) is due to expire on 31 December 2016. An important part of the Charter review process by which a new Charter is to be put in place (see DCMS 2015a) is the question of the future funding of the BBC: should the television licence fee be retained and modernised or is it time to consider other funding mechanisms, either as a supplement to the licence fee or to replace it altogether? While a spate of announcements in July 2015 suggests that parts of the licence fee settlement have already been agreed ${ }^{1}$ and substantive changes are likely to be pushed beyond the current Charter review, important questions remain concerning the current form and longer-term future of the UK's TV licence fee. The switchover to digital television, continuing expansion of pay TV and growth in online services make this an appropriate time to examine pressures on the existing system and to give considered thought to the alternatives.

Internationally, TV licence fees remain a common source of funding for public service broadcasting (PSB), ${ }^{2}$ especially in Europe (see details in Annex A). However, a handful of countries have already replaced their licence fee with an alternative funding system. In the Netherlands PSB has been funded out of general taxation since 2000. In 2013 Germany replaced its licence fee with a household levy, and in the same year Finland switched to an income-related tax.

While this article's focus is on the funding of PSB, its central thesis is that the questions of the purposes of PSB, the services that are provided and the funding system are intertwined and need to be considered together (see Figure 1). The purposes of PSB naturally guide its scale and scope, determining the services that are offered and the audiences these are aimed at. Purposes also influence the choice of funding mechanism as this may affect their achievement, for example by weakening universality of access under a subscription model or biasing content towards funding providers, whether the government or commercial organisations. There are also interrelationships between the funding model and the services provided. In one direction, service provision affects ease of collection, as the ability to exclude non-payers varies across distribution methods, as well as popular acceptance of the funding model. In the other direction, the incentives of the public broadcaster, like any other organisation, are linked with how it is funded: the funding model may affect the choice of services and the way in which these are directed and delivered. 


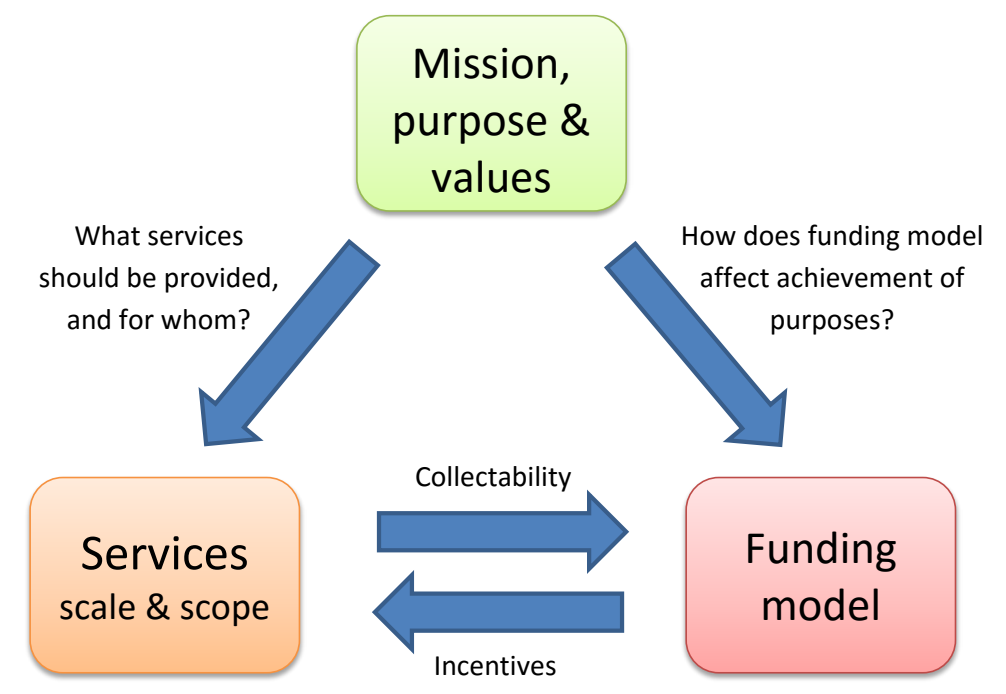

Figure 1: Interrelationship of purposes, services and funding of public service broadcasting.

The backdrop to this discussion is the profound impact of technological change on the media sector, which has dramatically altered the television landscape since the early-1990s in a number of ways:

- Huge expansion in distribution capacity through the growth of new platforms (cable and satellite since the late 1980s/early 1990s in the UK; Internet delivery assisted by faster broadband connections; mobile video enhanced by 4G/LTE networks) and digitisation of existing platforms (switchover to digital terrestrial television completed in the UK in 2012), resulting in a proliferation of channels, alongside the enormous amount of audio-visual content available online.

- Globalisation: online distribution facilitates cross-border access to audio-visual content, tending to integrate national broadcasting markets into global ones.

- Viewing on a variety of devices: not just the television set in the living room but also computers, laptops, tablets, smartphones, games consoles and digital recording devices.

- Ability to charge viewers due to conditional access systems on television distribution platforms and Internet paywalls.

Discussion of reforming the TV licence system is not new, and several of these developments were anticipated as long ago as the mid-1980s. Although the 1986 Peacock Report recommended retaining the TV licence fee (with modifications) in the near term and rejected advertising funding for the BBC, it foresaw a future without spectrum scarcity in which subscription would take over from the licence fee and viewers would choose for themselves 
what and how much to pay for (Peacock 1986). During the review leading up to the present BBC Charter, commentators including Cox (2004) and Elstein (2004) suggested separating PSB funding from the institution of the BBC, with any broadcaster being able to submit bids to a public broadcasting authority (or 'Arts Council of the Air') to receive funding for suitable programmes.

This article focuses on the funding issues raised in the current BBC Charter review. It takes as given the existence and present structure of the BBC, an analysis of which is beyond its scope. Although the discussion is phrased in terms of funding of the BBC, its principles could readily be applied to other public service broadcasters, in other countries as well as the UK, or to funding sources for a public broadcasting authority. Although the discussion takes place in the context of PSB in the UK and the BBC in particular, similar pressures are faced by PSB systems elsewhere and funding issues are also being considered in those countries.

Section 2 providesa brief discussion of the TV licence fee, describing the operation of the UK's TV licence system and the challenges that it now faces. Section 3 analyses the purposes of PSB - the system of public intervention in broadcasting of which the BBC forms a very large part - identifying its various rationales and considering in each case the nature of public broadcasting and implications for funding mechanisms. Section 4 assesses the performance of each funding model against the various purposes, highlighting its advantages and drawbacks. Based on these assessments, Section 5 summarises the performance of each model against a set of criteria and draws out recommendations for the future funding of the BBC.

\section{What is the TV licence fee?}

Any UK household that watches or records live TV as it is being broadcast, using any device - whether a television, computer, laptop, tablet, smartphone, games console, digital box or recorder - is required to hold a TV licence. A licence is required regardless of which channels or programmes are viewed: although the licence fee is used primarily to fund the BBC's television, radio and online services (see Annex B), it is payable even if the household views only free-to-air commercial channels, or pay TV, or content from overseas broadcasters, and never watches the BBC. The UK's public service broadcasters and their funding sources are detailed in Annex C.

The TV licence fee is officially classified as a tax: ${ }^{3}$ it has no explicit link with use of a service, and part of the revenue is top-sliced to fund various public purposes (as detailed in Annex B). Interestingly, the link between the licence fee and use of the BBC was stronger in 
the past than it is today: prior to 1955, when the BBC was the only show in town, the only reason to possess a television set was to watch the $\mathrm{BBC}$, and the licence fee was equivalent to a subscription (in the absence of conditional access technology). Successive market and technological developments have weakened the link between television ownership and watching the BBC. The launch of Independent Television (ITV) in 1955, followed by Channel 4 in 1982 and Channel 5 in 1997, meant that the BBC was no longer the only reason to have a TV, even for terrestrial viewers; however, the limited number of terrestrial channels meant that it remained a major one.

From the late 1980s onwards, the growth of multichannel cable and satellite pay TV further weakened the connection between television viewing and the BBC. Since the completion of digital switchover in 2012 all UK television households now have a choice of around 100 channels on terrestrial television, and many more on cable and satellite, of which just eight or nine come from the BBC. ${ }^{4}$ Against this backdrop it is no longer so reasonable to assume that all viewers would choose to have the BBC if this were a voluntary subscription. While the licence fee remains the most widely supported funding option for the BBC, it is no longer the majority choice ${ }^{5}$ and its popular acceptance may slip further as viewing time increasingly diverts elsewhere. Criticisms of the licence fee system include: its high collection costs, due in part to the absence of a conditional access system; use of criminal penalties to enforce payment; the regressive nature of the payment (being unrelated to income); and its unfairness (being unrelated to use). The last of these criticisms is a bigger issue now that all TV households are multichannel.

Adaptation of the licence fee system to changing technology is not a new issue. First established in 1923 to pay for radio broadcasts, the licence fee was extended to television in 1946 when the BBC recommenced its television service following the ending of World War II. ${ }^{6}$ The BBC began regular broadcasts in colour in July 1967; in 1968 a supplement for colour television was added to the licence fee. Today's technological challenge comes from the development of Internet delivery in the form of the BBC's online catch-up service, iPlayer. Currently a viewer may legally watch BBC programmes on iPlayer without a TV licence as long as viewing takes place only after the programme has been broadcast. With a small but growing number of viewers now accessing television services through Internetconnected devices rather than the television set, this 'iPlayer loophole' threatens the BBC's licence fee revenue, as well as being regarded by many people as an anomaly. ${ }^{7}$ 
The global accessibility of BBC content via iPlayer raises further issues. In an attempt to prevent access by viewers located outside the UK who have not paid for its content, the BBC implements geo-blocking, ${ }^{8}$ but this has two major flaws. First, geo-blocking restricts access by UK licence fee payers who happen to be travelling abroad: this 'portability' issue has recently been highlighted by UK Culture Secretary John Whittingdale (2015) and is also a target for the European Commission's digital single market (DSM) strategy. Second, geoblocking can readily be bypassed by overseas viewers using a virtual private network (VPN) to connect to a proxy server. It has been estimated that almost $65 \mathrm{~m}$ non-UK viewers approximately as many as the whole UK population - are accessing BBC programmes without payment in this way. ${ }^{9}$ Such viewing is liable to reduce the amounts overseas broadcasters are willing to pay for licensing of BBC content, undermining the income of its commercial subsidiary, BBC Worldwide.

Although the UK government appears to accept the need to modernise the licence fee to encompass viewing on iPlayer at any time, there is as yet little detail on precisely how this is to be achieved. Beyond simply extending liability for the licence fee to online viewing which takes place at any time - catch-up and on-demand as well as live - and relying on selfreporting, viewers might be required to enter their TV licence number in order to watch iPlayer. This would have the added advantage of tackling overseas viewing of iPlayer more effectively than the use of geo-blocking as non-payers - including those located outside the UK - could be excluded without eliminating portability for licence fee payers. However, for viewers who watch online only, this approach would effectively convert the licence fee into a voluntary subscription, required for viewing BBC content only, a fundamental shift in position that the BBC is unlikely to favour.

A direct extension of the principle of the TV licence to online viewing would require a TV licence for viewing any on-demand TV service (e.g. ITV Hub, All 4) and perhaps even any online audio-visual service (e.g. Netflix, Amazon Prime) - a suggestion that would surely be vehemently opposed by those providers. Another approach might be to add a TV licence fee (perhaps at a lower amount) to broadband and mobile phone subscriptions, these connections being the means by which online content is accessed (akin to television receiving equipment before the Internet age). However, Internet service providers (ISPs) and mobile operators could be expected to oppose such a move, and there would also be the issue of multiple payments by households (or even individuals) with several subscriptions. 


\section{Purposes of PSB}

To assess the suitability of alternative funding systems, this section identifies the purposes of PSB in today's world and considers what these imply as criteria for a desirable funding mechanism. $^{10}$

The public service mission to 'inform, educate and entertain' given to the $\mathrm{BBC}$ in the 1920s by its founding Director General, John Reith, can still be seen in UK's Communications Act 2003. To paraphrase, section 264 of the Act sets out the purposes of PSB as follows: the provision of programmes dealing with a wide range of subject matters, meeting the needs and interests of many different audiences; maintaining high standards in programme content and production quality; giving comprehensive and authoritative coverage of news and current affairs; and the provision of educational programming. These purposes can be divided into two broad concerns:

1. Consumer market failures: will the market deliver what people themselves want to watch, specifically the diversity and quality of programming needed to satisfy everyone’s tastes.

2. Citizenship concerns: programming that is important for educational, democratic or social reasons which we would like everyone - other people as well as ourselves - to watch.

At the heart of both concerns lie externalities associated with television programming, a textbook source of market failure. ${ }^{11}$ In economics an externality is an effect (either positive or negative) on one or more third parties that arises as a by-product of a production or consumption decision. For example, viewing of educational programming brings about wider benefits to society and the economy; these are positive externalities. The public policy concern is that programmes generating positive externalities are produced - the market will usually under-provide - and that these are actually watched, without which the intended benefit will not be realised.

\subsection{Consumer market failures}

Milton Friedman praised the market for its ability to give consumers the products that they individually desire. Comparing market provision with political systems where 'tyranny of the majority ${ }^{12}$ prevails, Friedman wrote,

[t]he characteristic feature of action through political channels is that it tends to require or enforce substantial conformity. The great advantage of the market, on the 
other hand, is that it permits wide diversity. It is, in political terms, a system of proportional representation. Each man can vote, as it were, for the color of tie he wants and get it; he does not have to see what color the majority wants and then, if he is in the minority, submit. (Friedman 1962, p. 15)

However, as pointed out by Waldfogel (2007), this is not always correct: when the market can support just a limited number of product types, the market caters for only the most popular tastes. Then individuals with minority tastes find that they cannot obtain their desired 'color of tie': there is the tyranny of the majority in market provision, just as in political representation. Waldfogel terms this phenomenon 'the tyranny of the market': for small groups with non-standard preferences, the market sometimes fails to deliver. ${ }^{13}$

At the heart of this problem lie preference externalities: by adding to or taking away from the majority taste, each consumer's preference affects the likelihood that other consumers are served. ${ }^{14}$ This interdependence can be seen when populations change over time: a small group of incomers with distinct preferences finds that its desires are not met, but as this group grows to form the majority its preferences come to dominate, and the original population may then find that its needs are no longer so well served. An individual benefits from a better matching of his or her own preferences when like-minded consumers come into the market and loses out when consumers with different tastes become the dominant group.

The incidence of tyranny of the market in broadcasting has altered with technological changes in the sector. The following describes the phenomenon in, respectively, analogue terrestrial television and today’s television landscape.

\subsubsection{Traditional market failures of analogue terrestrial television}

In analogue terrestrial television, spectrum scarcity severely limits the number of channels that can be transmitted, restricting the choice of programmes available to viewers at any moment in time. This tight constraint gives rise to tyranny of the market. The problem is worsened when lack of a conditional access system prevents viewers from paying directly for programming: instead commercial television relies on advertising revenues and will therefore aim to attract groups of highest value to advertisers, being the most numerous and/or those with the greatest propensity to purchase the advertised product or service. As the lengthy economics literature on market failures of analogue free-to-air television ${ }^{15}$ explains, this results in little diversity of programming with a tendency to duplicate mass market tastes while niche interests are under-served; low quality, because broadcasters cannot tap into 
consumer willingness to pay for better programmes; and excessive amounts of advertising, which tends to annoy viewers. The 'consumer' aspect of PSB can be interpreted as a remedy for these traditional market failures.

\subsubsection{New distribution platforms, digitisation and globalisation}

With the development of new distribution platforms and digitisation of existing ones, the capacity constraint of analogue terrestrial television has effectively disappeared. Entrants find it more worthwhile to serve niche audiences than further to subdivide the mass market, especially when also given the ability to charge viewers directly, as in pay TV. Globalisation of distribution aggregates pockets of demand in each country, facilitating the production of programmes serving minority tastes. However, this does not mean that all consumer preferences can be served: the substantial fixed cost of producing each programme must be covered collectively by the sales that the programme achieves, in competition with others; thus preference externalities are not entirely eliminated.

While these changes undoubtedly improve market provision for minority tastes compared with analogue terrestrial television, the outcome is not guaranteed to achieve the consumer optimum and distributional concerns may remain over provision for particular groups. While some commentators, such as Anderson (2004, 2006), point to the growth of the 'long tail' of niche products, other factors tend to increase the focus on a relatively small number of products. By facilitating global accessibility, Internet distribution may increase sales by the most talented artists or 'superstars' at the expense of weaker ones. ${ }^{16}$ Producers may respond to increased demand (e.g. due to globalisation) by investing more in each product, ${ }^{17}$ raising product quality but limiting the expansion of diversity. ${ }^{18}$ Evidence on search and recommendation systems is mixed: despite facilitating the discovery of new content, these can also create a rich-get-richer effect for popular products and reduce sales diversity. Theoretical analysis (see Weeds 2012) and empirical evidence ${ }^{19}$ suggest the coexistence of superstars and the long tail: although the long tail has grown, in sales terms it is a very skinny one and demand is increasingly concentrated on a small number of hits.

In addition, globalisation can result in the 'tyranny of alien majorities'. As Waldfogel (2007) explains, by diverting demand to foreign products, trade may undermine the viability of domestic content. Moreover, as domestic producers shift their focus towards global markets they are likely to reposition their output to suit international rather than local tastes. 
Accordingly, products which reflect local culture may be crowded out by homogenised global fare.

The tyranny of the market provides a rationale for some degree of intervention in television broadcasting. According to this 'consumer' purpose, PSB should aim to stimulate the production of content meeting the preferences of national, regional and minority groups that would not be well served in the global marketplace. Indeed, this concern is reflected in the objective of many national broadcasting regimes to increase production of content meeting local and national preferences.

Implications for PSB funding models are as follows. First, subscription is unproblematic: viewers desire the content and are willing to pay for it, although some subsidy from a licence fee, household levy or general taxation is likely to be required (otherwise why wouldn't the market provide?). There is also little reason to prohibit advertising: this provides useful additional revenue which, as long as the intensity of advertising is not excessive, benefits consumers and taxpayers by reducing the amount needed from other sources.

\subsection{Citizen concerns}

Viewing of certain television programmes can bring about wider benefits to society beyond the individual viewer. Television can be an educational tool; it is an important source of news and information; and it can play a role in shaping social values and building social cohesion. These benefits, which can be described as 'social externalities', give rise to another form of market failure. There are two main categories of social externalities in television, described next.

\subsubsection{Political information and debate}

Television is an important source of political information and forum for debate. Economics literature in the area, surveyed by Strömberg (2015), highlights two key roles for the media in politics: ensuring that voters are fully informed and monitoring the actions of elected representatives. Since in a democracy all citizens are affected by such outcomes, these involve positive externalities, and coverage of news and current affairs is likely to be underproduced and under-consumed from the social perspective.

A further concern is the possibility of media bias: media coverage may favour certain politicians or interest groups in order to influence democratic decisions. This concern is reflected in the media plurality rules in UK merger control, intended to ensure that the number of distinct voices and opinions being expressed is not unduly diminished. The 
broadcasting code of the Office of Communications (Ofcom), the regulator and competition authority for the UK's communications industries, requires impartiality and accuracy in news reporting by all television broadcasters. Another protection against media bias is the existence of independent and trusted news broadcasters - including, but not only, the BBC which would not wish to forfeit their reputation for high quality and impartial news coverage. $^{20}$

Political considerations have the following implications for the funding of PSB. The need for news media to be independent of government and interest groups calls for funding sources that are free from political control: direct funding out of general taxation would give the government of the day undue influence over the public broadcaster, and even a licence fee or household levy is not entirely free from political influence if there is government involvement in determining its level, as is likely given that this is a form of taxation. ${ }^{21}$ Advertising funding carries a danger of bias in favour of major advertisers, ${ }^{22}$ though it should be noted that other UK public service broadcasters, notably Channel 4 and ITV, are entirely advertising-funded and yet are highly regarded news reporters, suggesting that this problem is not insurmountable.

Perhaps the only source of funding which is free from political or interest group influence is subscription, whereby payment is decentralised to individual viewers. But the exclusion of non-payers tends to conflict with the aim of stimulating viewing of programming with positive externalities. If subscription is found to limit viewing, especially by less well-informed groups whose engagement might be of particular concern, then wider social benefits will fail to be realised. In any case, the presence of positive externalities suggests that market provision via subscription will under-provide news and current affairs programming, calling for supplementary funding from another source to mitigate underproduction.

\subsubsection{Education and social values}

Television can play a role in educating us and shaping our social values. Recent empirical studies, comprehensively surveyed in DellaVigna and La Ferrara (2015), identify positive effects of television viewing in promoting various educational and social policy aims, including: 
- Education: Television access is found to raise English standards for children of immigrants in the United States; Sesame Street, a programme for preschool children, is found to have a positive impact on achievement in school.

- Fertility: Brazilian soap operas ('novelas') which provide role models of smaller families have a significant impact on family size; the American reality television series 16 and Pregnant is found to increase Google searches and Twitter messages containing birth control-related terms during and after the broadcast and to reduce births to teenage mothers in the following 18 months.

- Health: There is some evidence that soap operas can raise awareness of health issues and perhaps influence behaviour.

The proliferation of audio-visual content available to viewers poses a particular challenge to the effectiveness of PSB interventions aimed at social and educational purposes. These benefits come about only if the relevant programming is watched, but viewers' choices are driven by their desire for entertainment, and an enormous amount of content is now available to choose from. This competition for attention makes it difficult for socially worthy programming to gain a large audience and achieve its purposes. ${ }^{23}$ Recognising this point, John Reith believed in the 'brute force of monopoly' as a means for the BBC to control what people watched; this is not remotely possible now. The problem facing PSB was put succinctly by Richard Eyre, then Chief Executive of ITV, in 1999:

[f]ree school milk doesn't work when the kids go and buy Coca-Cola because it's available and they prefer it and they can afford it. So public service broadcasting will soon be dead. (Eyre 1999, p. 5)

One way to mitigate this problem is an approach akin to 'product placement' used by advertisers: integrating public service messages into popular programmes. ${ }^{24}$ When this is understood the following comment by then Culture Secretary Tessa Jowell, criticised in the press at the time, makes a lot of sense:

those episodes of EastEnders that tackle difficult issues of child abuse, drug taking, teenage pregnancy, and so forth, are actually - when they do it responsibly providing an important public service. (Quoted in The Independent 2004) 
On the assumption that the challenge of gaining viewer attention can be met, social externalities justify some degree of public subsidy for suitable programming. Since the benefits accrue to society as a whole and not just to television viewers, there is an argument for using a broader form of taxation than the TV licence fee, with the choice between general taxation and a household levy depending on other factors such as distributional concerns (which might favour the former) and the stability of funding for the BBC (which would favour the latter). The need to promote viewing of socially beneficial programming militates against subscription funding as the exclusion of non-payers is likely to conflict with this aim. Advertising finance poses no particular problem; the intensity of advertising should be determined by balancing its annoyance to viewers, which may reduce viewing, against the increase in programme expenditure and reduced need for funding from other sources that it allows.

\section{Assessment of alternative funding models}

The main alternatives to the existing TV licence fee system are as follows:

- modernised licence fee, reformed to close the iPlayer loophole;

- universal household levy paid by all UK households, not just those that watch television, perhaps with some concessions;

- voluntary subscription, as part of a hybrid funding model alongside the licence fee or a household levy;

- direct government funding out of general taxation; and

- advertising and sponsorship revenue from the sale of advertising airtime, programme sponsorship and product placement.

The UK government's consultation paper for the BBC Charter review (DCMS 2015a) puts forward the first three options, while dismissing the other two. A sixth source of funding should also be borne in mind as a supplement to revenue from the licence fee or an alternative system:

- Commercial income, largely from licensing of BBC programmes to overseas broadcasters.

Drawing on the analysis in Section 3, this section assesses the relative merits of the possible funding sources for the BBC. 


\section{1. $\quad$ Modernised licence fee}

If we leave aside the implementation issues already discussed above, there are a number of advantages to a modernised licence fee. One is its near-universality: since payment is compulsory for all TV viewers, it does not deter viewing except by a very small number of people who then decide not to watch television at all. This aspect is important for content that confers positive social externalities, for which broad reach is desirable, but less important in the case of preference externalities since once the content is available the relevant consumers will subscribe voluntarily. Once the level of the licence fee is fixed the system is independent of government - an important consideration for political independence - but the current institutional arrangements for setting the UK's licence fee leave scope for political influence. Being a compulsory payment with a stable base (on the assumption that the threat from online viewing is removed), the licence fee generates predictable income for the BBC.

The licence fee has a number of drawbacks, however. Collection is expensive, especially when costs to the criminal justice system are added in, ${ }^{25}$ compliance is not universal $^{26}$ and the effectiveness of enforcement is limited by reliance on self-reporting and visits to unlicensed premises rather than a technological conditional access system. Being unrelated to income, the fee is regressive, and criminalisation of licence fee evaders - with the possibility of imprisonment for non-payment of the fines imposed for evasion - is controversial. ${ }^{27}$ Popular acceptance of the licence fee may fall further as viewers spend less time watching BBC programmes and increasingly come to regard a payment that is unrelated to use of its service as unfair.

A less obvious implication of the licence fee system is the BBC's institutional need for popularity. In order to maintain popular support for the licence fee the BBC has to provide 'something for everyone', running the risk of confusing the (desirable) aim of achieving large audiences for programming that serves public purposes with the (more debatable) aim of chasing ratings for their own sake. It matters what types of programming achieve large audiences; as Patricia Hodgson, then Chief Executive of the Independent Television Commission (ITC) and now Chairman of Ofcom, put it when she contrasted the populist Celebrity Sleepover and nature documentary The Blue Planet,

Beating ITV with Blue Planet is a triumph! Beating it with Celebrity Sleepover is a tragedy! (Hodgson 2002, p. 11) 


\subsection{Household levy}

According to recent press reports (Sweny 2015; Plunkett and Martinson 2015), a household levy is the funding model favoured by the BBC and the UK Department of Culture, Media and Sport (DCMS). As well as being simpler to implement than the proposed modernisation of the licence fee, a household levy would have a number of advantages over the present system. Collection and enforcement costs could be kept down by linking with existing household payments such as council tax or a utility bill, and criminalisation of non-payers could then be abolished. The levy could be banded or exemptions applied for low-income groups to make it progressive. The BBC's income would be stable and predictable, probably more so than under the licence fee.

As a means of achieving the widest possible reach for programming that confers social externalities, a household levy is advantageous: access to BBC services would be fully universal, unlike under the licence fee, as there would be no incentive to forgo television in order to avoid payment. On the other hand, a household levy is arguably more unfair than the licence fee as it also draws in those with no interest in watching television. However, on the basis that viewing certain television content generates wider benefits to the whole of society, it is perhaps justified that all beneficiaries - rather than just television viewers (to the extent that these are not all the same people) - contribute to its production. Like the licence fee a household levy generates an incentive towards 'something for everyone' programming in order to maintain popular acceptance of the funding system, which may at times overtake public service objectives.

As for the licence fee, once its level is determined a household levy would be independent of government. However, depending on what institutional arrangements are put in place for setting the levy there may be scope for political influence at this point, so the implications for the BBC’s political independence are again not clear-cut.

\subsection{Direct government funding}

Like a household levy, government funding out of general taxation links payment for socially valuable programming to all beneficiaries rather than television viewers, in keeping with the social externalities rationale for PSB. It removes the need to collect a distinct TV-related charge, so avoiding additional collection costs, and to the extent that the tax system is progressive it improves upon the regressive character of the licence fee. Government funding might also lessen the BBC’s need to court popularity as viewers no longer pay for it directly, 
which may improve incentives to produce content that is of public value rather than merely popular. On the other hand, the BBC's connection with its viewers might be lessened as its accountability shifts more obviously to the government.

There are two major drawbacks of direct government funding. By making its funding directly and continually dependent on the government, it places the BBC's political impartiality at far greater risk than under either the licence fee or a household levy. This factor alone militates strongly against this approach. The BBC’s funding would also become much less stable, being subject to current pressures on the public purse. Indeed, in the current fiscal environment of austerity, far from the BBC being brought onto the government's books, the UK has instead seen public costs being transferred to the BBC. Consequently this approach is highly unlikely to be adopted.

\subsection{Subscription}

By being directly linked with television viewing and allowing viewers to pay for what they want, perhaps with different tiers or packages, subscription is fair in the sense that the greatest beneficiaries pay the most. Many viewers are now familiar with the concept of paying for television, and more will become so as online audio-visual services develop further. As Gavyn Davies foresaw in 1999,

the digital age will increasingly be one in which many or most consumers of television pay for packages closely tailored to their needs. As they become more accustomed to choice, to subscription and to pay-per-view, it could be that the licence fee will come to seem an anachronism. (Davies 1999, p. 144)

With the amount(s) being set by the BBC and payment decentralised to individual viewers, subscription would make funding entirely independent of government and vested interests. Accordingly a subscription system would protect the BBC's political impartiality and is superior to the other funding options in this regard.

Subscription is an appropriate funding system for programming that is purely of private benefit: willingness to pay is a more reliable measure than surveys of what consumers actually value, and the need to attract subscribers gives the provider a strong incentive to produce the programmes that viewers want. However, as a funding model for programming that generates wider social benefits, subscription has a number of drawbacks. First, the loss of universality - as some people choose not to subscribe - conflicts with the need for broad 
reach to bring about social aims. Second, subscription creates a strong incentive for populist programming, in a more direct way than the other funding systems noted above. Finally, the implications for collection costs are mixed: while enforcement can be simplified relative to the licence fee by using a conditional access system, the need to attract and bill subscribers incurs marketing and subscriber management costs. There would also be an up-front cost of setting up an encryption system for the digital terrestrial television (DTT) platform on which most viewers currently access programmes using a free-to-air receiver.

Subscription on its own is insufficient to fund the types of programming discussed in Section 3: some additional subsidy from public sources is needed (otherwise why wouldn't the market provide?). However, this does not necessarily imply that no subscription funding should be used, at least for programming whose value accrues to the individual consumer with few wider social benefits. Moreover, if the BBC wishes to produce purely populist programming, there is little reason why this should not be subscription-funded, and no subsidy is required for this.

\subsection{Advertising and sponsorship}

For advertisers as for public broadcasters, reach is highly important. In this sense advertising funding complements rather than conflicts with public objectives. However, the audience groups most desired by advertisers are not necessarily the same as those which might be the focus of public broadcasting. Thus, despite the shared desirability of reach it is possible that the targeting of content to maximise advertising revenues may be somewhat different from the pursuit of social aims.

Advertising funding is independent of government, supporting political independence. While concern might be raised that programme content could be influenced by advertisers' interests, potentially resulting in the suppression of adverse reports about large corporations, the success of other public service broadcasters (such as the UK's Channel 4 and ITV) in operating respected news services despite reliance on advertising funding suggests that this danger is not insurmountable.

Advertising and programme sponsorship could be used alongside any of the above funding methods to reduce the funding requirement from viewers and/or taxpayers. Even pay TV channels often carry advertising: although viewers may suffer some annoyance from advertising, they benefit from lower subscription charges and/or greater programming investment than would otherwise be possible. 
Although other advertising-funded broadcasters could be expected to lobby against competition from the BBC in the supply of advertising airtime, advertisers would benefit from the increased availability of advertising airtime and the ability to reach individuals who watch little television other than the BBC. Interestingly, when in 2008 French President Nicolas Sarkozy announced a plan to ban the country’s public broadcasters from carrying advertising, he was criticised for removing $€ 800$ million (£600 million) in advertising revenue from public broadcasting and handing this to his media tycoon friends.

\subsection{Commercial income, especially from overseas}

Commercial income, consisting largely of licensing fees paid by overseas broadcasters for BBC programmes, makes a small but useful contribution to the BBC's budget: in 2014-15 the BBC’s commercial arm, BBC Worldwide, contributed $£ 226.5 \mathrm{~m}$ to the BBC's PSB arm (BBC 2015, p. 135). While this may appear to be a 'free lunch', converting the domestic popularity of many BBC programmes into commercial successes overseas, there are two issues to consider.

The first issue is the ease of overseas access to BBC content via iPlayer and the challenge this presents to the way in which the BBC makes its content available to UK viewers. As discussed in Section 2, geo-blocking is an imperfect solution to this problem. A more effective method of blocking access to iPlayer by overseas viewers, perhaps by requiring a TV licence number and UK address to be entered, would protect the licensing fees paid by overseas broadcasters for BBC programmes. The BBC may prefer to launch international versions of iPlayer, with a different selection of programmes and tailored pricing, as a means of accessing overseas demand directly; indeed, it has recently been reported that the BBC plans to launch an online subscription service in the US in 2016, hoping to earn a £30m annual return (Mance 2015). The European Commission has also expressed a desire to see iPlayer made available to consumers elsewhere in the EU (although no proposals have yet been put forward): Andrus Ansip, Vice President in charge of the Commission's DSM strategy is reported as saying at a stakeholder forum in Brussels on 24 February 2015:

. . . you can only download or stream BBC iPlayer TV programmes while you are inside the UK. In the off-line world this would be called discrimination. In the online world it happens every day. I want to pay, but I am not allowed to. I lose out, they lose out. How can this be a good thing? (Mundell 2015) 
A less obvious concern is the possibility that the desire to earn overseas revenues comes to exert a greater influence on programme content. Waldfogel (2007) notes the effect of cross-border trade in 'globalising' the character of audio-visual products: as US movie studios became more focused on winning international audiences, they repositioned their output towards global tastes and shifted away from idiosyncratic American interests. If BBC content were to become driven more by the need to earn commercial revenues in international markets rather than purely serving UK viewers and domestic public purposes, its effectiveness in achieving the latter aims may be weakened.

\section{Summary and recommendations}

Table 1 summarises the performance of the five main funding models for PSB (omitting commercial income, which can supplement any system) on a range of criteria.

Table 1: Summary of funding models' performance on five criteria

\begin{tabular}{lccccc}
\hline Funding model & Broad reach & $\begin{array}{c}\text { Political } \\
\text { independence }\end{array}$ & $\begin{array}{c}\text { Incentive toward } \\
\text { social value }\end{array}$ & Fairness & $\begin{array}{c}\text { Collection and } \\
\text { enforcement }\end{array}$ \\
\hline Licence fee & $(\checkmark)$ & $?$ & $?$ & $\mathbf{x}$ & $\mathbf{x}$ \\
Household levy & $\checkmark$ & $?$ & $?$ & $?$ & $\checkmark$ \\
Govt. funding & $\checkmark$ & $\boldsymbol{x}$ & $\mathbf{x}$ & $\checkmark$ & $\checkmark$ \\
Subscription & $\mathbf{x}$ & $\checkmark$ & $\mathbf{r}$ & $?$ \\
Advertising & $(\checkmark)$ & $(\checkmark)$ & $\mathbf{x}$ & $\checkmark$ & $\checkmark$ \\
\hline
\end{tabular}

$\checkmark=$ criterion achieved; $(\checkmark)=$ caveats to achievement of criterion; $\mathbf{x}=$ criterion not achieved; ? = questionable or mixed outcome.

Table 1 suggests that the licence fee - even when modernised to capture iPlayer - is dominated by a household levy, which is superior or similar in performance on every criterion. By overcoming the incentive for a few individuals to forgo television in order to avoid the licence fee, a household levy supports truly universal reach. The levy can be made progressive with a banding system or exemptions, although the fairness may be debated of imposing the charge on households that have no interest in watching television themselves but may benefit from the social purposes promoted by the viewing of others. Collection and enforcement of a household levy is simpler and cheaper than for the licence fee, which should also facilitate decriminalisation (again boosting fairness). The political independence of either charging system is sensitive to the process by which its amount is set; the current mechanism could be improved upon by establishing an independent commission similar to Germany’s Kommission zur Ermittlung des Finanzbedarfs der Rundfunkanstalten (KEF). In relying on broad popular support, the two systems similarly generate an incentive for populist 
over socially beneficial programming. Taken in the round, this analysis suggests that the licence fee should be abandoned in favour of a household levy, or another system.

Despite scoring well on other criteria, government funding out of general taxation conflicts with the need to protect the BBC's political independence, and for this reason alone it is not a strong contender to replace the licence fee. The likely instability of the funding stream may also harm programme investment. In any case, this approach would run against the tide of the current environment of fiscal austerity in which costs are instead being shifted from central government on to the licence fee, making it highly unlikely to be adopted.

Subscription is a poor funding model for content that generates significant social externalities as it restricts access and directs programming towards paying viewers rather than enhancing social value. In its favour, as a decentralised payment system it is the least susceptible to political or interest group influence, but there is a tension between these two aspects. If political independence rather than externalities is the overriding concern, subscription may be a desirable funding model for a news service; however, this would be a move away from the BBC's long-standing role as the primary source of television news for many viewers. Subscription might be best considered as a supplement to a free-to-air service funded from a licence fee or household levy, used to fund encrypted premium channels which are of interest to limited groups of viewers and which confer few external benefits. Viewers' growing familiarity with paying for their chosen content from multiple providers also supports this approach. Even then, tyranny of the majority must be borne in mind: the market's tendency to underserve minority groups with limited ability to pay is one of the rationales for public intervention in broadcasting.

Advertising funding has a number of advantages: it promotes broad reach, though not necessarily sharing the same target audience as public broadcasting; it avoids the perceived unfairness of most of the other systems; and it is straightforward to collect. Independence from government is strong, and the evidence from other public broadcasters suggests that any conflict of interest with major advertisers is manageable. While advertising creates some annoyance for viewers, when the intensity of advertising is modest this is offset by the reduced need for funding from viewers or taxation and the availability of additional funds for programme investment. Other than tradition, there seems little reason for advertising on the BBC to be disregarded.

To conclude, while modernising the TV licence fee to close the iPlayer loophole would patch up the gap that has opened in the current system, remedying its most obvious 
defects, it would be preferable to replace the licence fee altogether as it is dominated by other funding models. The closest replacement, sharing and extending its benefits with fewer of its drawbacks, would be a household levy. Despite some advantages, direct government funding should be ruled out due to its susceptibility to political influence. Subscription may be a useful top-up for non-essential services where achieving broad reach is less important. Meanwhile, in the light of public funding pressures perhaps it is time for the historical ban on the carrying of advertising by the BBC to be reconsidered. 


\section{Annex A}

\section{Funding of public service broadcasters around the world}

Table A1 sets out the funding sources for public service broadcasters in a number of countries. Licence fees remain commonplace, being found in Denmark, France, Ireland, Italy, Japan, Norway and Sweden (this list is not exhaustive). In a few countries (Australia, Canada and the Netherlands) the public broadcaster is directly funded by the government. In some countries (Canada, France, Germany and Ireland) public broadcasters also carry advertising, in contrast with the BBC, although the BBC's public service counterpart Channel 4 is funded entirely from advertising revenue.

Table A1: International comparison of funding for public service broadcasters (2014)

\begin{tabular}{llcc}
\hline Country & Main source of finance & Annual amount (euros) & Advertising? \\
\hline Australia & Government grant & n/a & No \\
Canada & Government grant & n/a & Yes \\
Denmark & Licence fee & 327 & No \\
Finland & Income-related tax & 140 (max) & Yes \\
France & Licence fee & 133 & Yes \\
Germany & Household levy & 216 & Yes \\
Ireland & Licence fee & 160 & No \\
Italy & Licence fee & 113 & No \\
Japan & Licence fee & 132 & Yes \\
Netherlands & Government grant & n/a & No \\
Norway & Licence fee & 365 & No \\
Sweden & Licence fee & 238 & No (but Channel 4 \\
United Kingdom & Licence fee (BBC only) & 179 & entirely ad-funded) \\
& &
\end{tabular}

Notably, two countries have recently reformed their funding model, abandoning a licence fee system in favour of different alternatives. In 2013 Germany replaced its licence fee with a household levy. This is charged at a flat rate per household with exemptions for certain low-income groups (e.g. welfare claimants and students); businesses also pay the levy. In the same year Finland replaced its licence fee with an income-related tax, hypothecated to the funding of its public broadcaster, YLE (and hence known as the 'YLE tax’). The payment is a fixed percentage of income with an upper limit of $€ 140$ per person and an exemption for low incomes; as in Germany, businesses are also liable for the tax (House of Commons Culture, Media and Sport Select Committee 2015). 


\section{Annex B}

\section{BBC funding and expenditure}

The UK’s TV licence fee is currently set at $£ 145.50$ per year for a colour licence, raising total revenue of $£ 3,735 \mathrm{~m}$ in 2014/15 (BBC 2015, p. 134). In addition the BBC receives income from its commercial subsidiary, BBC Worldwide, which contributed £226.5m to the BBC’s PSB division in 2014/15, representing around 5.5 per cent of the latter's annual budget (BBC 2015, p. 135).

Most of the BBC's licence fee and other revenues are used to fund its television, radio, online and 'red button' (information) services and to cover licence fee collection costs, but a small amount is top-sliced to provide content and services for the Welsh language broadcaster S4C and to fund a variety of additional public purposes including rural broadband and the BBC World Service (see Table A2). From 2018-19 the BBC will take on responsibility for funding free TV licences for the over-75s at an anticipated cost of $£ 250 \mathrm{~m}$ in 2018-19, rising to $£ 450 \mathrm{~m}$ in 2019-20 and £750m in 2020-21(Martinson and Plunkett 2015). From 2020 the BBC is to be granted control over the over-75s policy which may allow it to reduce the subsidy.

Table A2: Expenditure of the BBC (PSB Group), 2014/15, £m

\begin{tabular}{lr}
\hline TV & $2,367.8$ \\
Radio & 652.5 \\
BBC Online \& Red Button & 201.0 \\
S4C & 107.0 \\
BBC World Service & 253.6 \\
Licence fee collection & 101.4 \\
Broadband rollout & 150.0 \\
Digital switchover & 0.4 \\
Local TV & 2.9 \\
Other & 385.3 \\
TOTAL OPERATING EXPENDITURE & $4,221.9$
\end{tabular}

Source: BBC (2015). 


\section{Annex C}

\section{UK public service broadcasters}

Table A3 summarises the UK public service broadcasters, detailing for each its ownership structure (public corporation or commercial company), accountability and regulation, rights, duties and funding sources.

Table A3: Summary of UK public service broadcasting

\begin{tabular}{|c|c|c|c|c|}
\hline Broadcaster & $\begin{array}{l}\text { Ownership; } \\
\text { accountability; } \\
\text { regulator(s) }\end{array}$ & Rights & Duties & Funding \\
\hline $\mathrm{BBC}$ & $\begin{array}{l}\text { Public (statutory } \\
\text { corporation); } \\
\text { Licence fee payers, } \\
\text { Parliament, citizens; } \\
\text { BBC Trust, Ofcom }\end{array}$ & $\begin{array}{l}\text { Funding } \\
\text { Spectrum } \\
\text { 'Must carry' rules } \\
\text { EPG prominence }\end{array}$ & $\begin{array}{l}\text { Public service remit } \\
\text { Universal availability }\end{array}$ & Licence fee \\
\hline $\begin{array}{l}\text { Channel } 4 \text { / } \\
\text { S4C (Wales) }\end{array}$ & $\begin{array}{l}\text { Public (statutory } \\
\text { corporation); } \\
\text { Parliament, citizens; } \\
\text { Ofcom (S4C: also S4C } \\
\text { Authority) }\end{array}$ & $\begin{array}{l}\text { Spectrum } \\
\text { 'Must carry' rules } \\
\text { EPG prominence }\end{array}$ & $\begin{array}{l}\text { Public service remit, } \\
\text { ‘innovative’ character } \\
\text { Universal availability }\end{array}$ & $\begin{array}{l}\text { Advertising } \\
\text { (S4C: also some } \\
\text { funding from } \\
\text { BBC) }\end{array}$ \\
\hline $\begin{array}{l}\text { ITV, } \\
\text { Channel } 5\end{array}$ & $\begin{array}{l}\text { Commercial company; } \\
\text { Shareholders; } \\
\text { Ofcom }\end{array}$ & $\begin{array}{l}\text { Spectrum fee } \\
\text { reduction } \\
\text { 'Must carry' rules } \\
\text { EPG prominence }\end{array}$ & $\begin{array}{l}\text { Public service remit } \\
\text { (now more limited) } \\
\text { Universal availability }\end{array}$ & Advertising \\
\hline
\end{tabular}

Note: Electronic programme guide (EPG) prominence means that the channel is given one of the top slots in the channel listing. 


\section{References}

Anderson, C. (2004) 'The Long Tail’, Wired Magazine 12, 170-7.

Anderson, C. (2006) The Long Tail. London: Random House Business Books.

Anderson, S. and J.Waldfogel (2015) 'Preference Externalities in Media Markets', ch. 1 in S. Anderson, J. Waldfogel and D. Strömberg (eds), Handbook of Media Economics, vol. 1A. Amsterdam: Elsevier North-Holland.

Armstrong, M. and H. Weeds (2007) 'Public Service Broadcasting in the Digital World', in P. Seabright and J. von Hagen (eds), The Economic Regulation of Broadcasting Markets: Evolving Technology and Challenges for Policy. Cambridge: Cambridge University Press. BBC (2015) BBC Annual Report and Accounts 2014/15. London:

BBC. http://downloads.bbc.co.uk/annualreport/pdf/2014-15/bbc-annualreport-201415.pdf (accessed 21 December 2015).

BBC Trust (2015) Response to the Department for Culture, Media and Sport's Charter Review Consultation. Technical Annex C: Funding. October. http://downloads.bbc.co.uk/bbctrust/assets/files/pdf/about/how_we_govern/charter_revie w/annex_c_funding.pdf (accessed 21 December 2015).

Cox, B. (2004) Free for all? Public Service Television in the Digital Age. London: Demos.

Davies, G. (1999) The Future Funding of the BBC. Report of the Independent Review Panel London: Department for Culture, Media and Sport. http://news.bbc.co.uk/hi/english/static/bbc_funding_review/reviewco.pdf (accessed 21 December 2015).

DCMS (Department for Culture, Media and Sport) (2015a) BBC Charter Review Public Consultation, 16 July-8 October 2015. London:

DCMS. https://www.gov.uk/government/uploads/system/uploads/attachment_data/file/44 9830/DCMS_BBC_Consultation_A4_1_.pdf (accessed 21 December 2015).

DCMS (2015b) TV Licence Fee Enforcement Review. Presented to the Houses of Parliament pursuant to section 77 of the Deregulation Act 2015. https://www.gov.uk/government/uploads/system/uploads/attachment_data/file/4452 12/166926_Perry_Review_Text-L-PB.pdf (accessed 21 December 2015). 
DellaVigna, S. and E. La Ferrara (2015) 'Economic and Social Impacts of the Media', ch. 19 in S. Anderson, D. Strömberg and J. Waldfogel (eds), Handbook of Media Economics, vol.1A. Amsterdam: Elsevier North-Holland.

Elstein, D. (2004) Beyond the Charter: The BBC after 2006. Report of the Broadcasting Policy Group chaired by David Elstein. London: Premium Publishing.

Eyre, R. (1999) ‘Public Interest Broadcasting - A New Approach’, James MacTaggart Memorial Lecture, Guardian Edinburgh International Television Festival, 27 August 1999. Available at http://www.thetvfestival.com/website/wpcontent/uploads/2015/03/GEITF_MacTaggart_1999_Richard_Eyre.pdf (accessed 21 December 2015).

Farchy, J., M. Gansemer and J. Petrou (2013) ‘E-book and Book Publishing’, ch. 31 in R. Towse and C. Handke (eds), Handbook on the Digital Creative Economy. Cheltenham and Northampton, MA: Edward Elgar.

Friedman, M. (1962). Capitalism and Freedom. Chicago, IL: University of Chicago Press.

Hodgson, P. (2002) 'Freedom to Flourish: The Future of Communications', Royal Television Society Fleming Lecture, 5 March. Available at http://www.ofcom.org.uk/static/archive/itc/the_key_issues/presentations_speeches_rep orts/index.asp.html (accessed 21 December 2015).

House of Commons Culture, Media and Sport Select Committee (2015) Future of the BBC: Fourth Report of Session 2014-15 (HC

315). http://www.publications.parliament.uk/pa/cm201415/cmselect/cmcumeds/315/315.p df (accessed 21 December 2015).

Independent (2004) 'Watching with Tessa’, 2 March.

Mance, H. (2015) 'BBC to launch Netflix-style service in US', Financial Times, 17 September.

Martinson, J. and J. Plunkett (2015) 'BBC to take on £750m cost of subsidy for over-75s in licence fee deal', Guardian, 6 July.

Mundell, I. (2015) 'Geoblocking targeted in digital single market strategy’, Politico, 24 February. 
Oborne, P. (2015) 'Why I have resigned from the Telegraph', openDemocracyUK, 17 February. https://www.opendemocracy.net/ourkingdom/peter-oborne/why-i-haveresigned-from-telegraph (accessed 21 December 2015).

ONS (Office for National Statistics) (2006) News Release: Classification of Public Sector Television. 20 January. London: ONS.

Peacock, A. (1986) Report of the Committee on Financing the BBC (Cmnd 9824). London: HMSO.

Plunkett, J. and J. Martinson (2015) 'BBC licence fee replacement gets backing from culture secretary’, Guardian, 9 September.

Revoir, P. (2015) 'BBC iPlayer "watched by more than 60 million people outside the UK for free”, Guardian, 21 July.

Rosen, S. (1981) 'The Economics of Superstars’, American Economic Review 71, 845-58.

Strömberg, D. (2015) 'Media Coverage and Political Accountability: Theory and Evidence', ch. 13 in S. Anderson, D. Strömberg and J. Waldfogel (eds), Handbook of Media Economics, vol.1A. Amsterdam: Elsevier North-Holland.

Sutton, J. (1991) Sunk Costs and Market Structure. Cambridge, MA: MIT Press.

Sweny, M. (2015) 'BBC backs replacing licence fee with universal levy’, Guardian, 7 September.

TV Licensing (2015) Switched On: TV Licensing Annual Review 2014/2015. http://www.tvlicensing.co.uk/ss/Satellite?blobcol=urldata\&blobheadername1 =contenttype\&blobheadervalue1=application\%2Fpdf\&blobkey=id\&blobtable=MungoBlobs\&blob where $=1370006281969 \&$ ssbinary $=$ true (accessed 21 December 2015).

Waldfogel, J. (2007) The Tyranny of the Market: Why You Can't Always Get What You Want. Cambridge, MA: Harvard University Press.

Weeds, H. (2012) 'Superstars and the Long Tail: The Impact of Technology on Market Structure in Media Industries', Information Economics and Policy 24(1), 60-8.

Weeds, H. (2013) 'Digitisation, Programme Quality and Public Service Broadcasting’, ch. 2 in R. Picard and P. Siciliani (eds), Is there Still a Place for Public Service Television? Effects of the Changing Economics of Broadcasting. Oxford Reuters Institute and BBC Trust. 
Whittingdale, J. (2015) Culture Secretary keynote to Royal Television Society Cambridge Convention. Gov.UK, 16 September. https:/www.gov.uk/government/speeches/culturesecretary-keynote-to-rts-cambridge-convention (accessed 20 December 2015). 


\section{Notes}

${ }^{1}$ On 7 July 2015 it was revealed that, in a behind-closed-doors deal, the BBC had agreed to absorb the cost of free TV licences for the over-75s and in return the government had agreed to increase the TV licence fee in line with inflation, end top-slicing to fund rural broadband, and close the 'iPlayer loophole' (see Section 2).

${ }^{2}$ While the article continues to refer to the system as public service broadcasting, its extension into non-linear on-demand distribution suggests this should perhaps now be termed public service media.

${ }^{3}$ In January 2006 the UK's Office of National Statistics (ONS) reclassified the TV licence fee as a tax rather than a service charge, stating by way of explanation that 'the licence fee is a compulsory payment which is not paid solely for access to BBC services’ (ONS 2006).

${ }^{4}$ At the time of writing the BBC channels are: BBC One, BBC Two, BBC Three, BBC Four, BBC News, BBC Parliament, CBBC, CBeebies and BBC Alba; on the DTT platform the last of these is available in Scotland only. From February 2016 BBC Three will become online-only, viewable through BBC iPlayer.

${ }^{5}$ In a quantitative survey conducted as part of the BBC Trust's public consultation on the three funding options for the BBC proposed in DCMS (2015a), 35\% of respondents preferred a modernised licence fee, 24\% preferred a licence fee topped up with subscription and 23\% preferred a universal household levy (with 18\% replying 'don't know/none of these'). However the report comments in paragraph 5 that ' $[\mathrm{t}]$ he results do suggest some confusion around what the new household levy and the topped up licence fee would involve in practice. This indicates that the public would require a greater level of detail on how the system would work in practice in order to form an educated opinion’ (BBC Trust 2015, p. 4).

${ }^{6}$ The BBC first launched a regularly scheduled television service on 2 November 1936 but this was suspended at the outbreak of World War II in 1939.

${ }^{7}$ Note that the availability of BBC services without payment is not exceptional: since 1971 radio listening has not required a licence, and the BBC's Internet services - including its popular BBC News website - are also exempt. However, an exemption for accessing the same content at different times seems anomalous.

8 'Geo-blocking' refers to the practice of restricting access to Internet content based on users' geographic location, usually identified from their IP address.

${ }^{9}$ Estimate obtained from a survey by GlobalWebIndex (Revoir 2015).

${ }^{10}$ A more detailed analysis of the rationale for PSB can be found in Weeds (2013).

${ }^{11}$ While market failure may not be the only rationale for PSB, it is the approach that provides the clearest guide to where public intervention is needed and the form this should take. As Gavyn Davies wrote in 1999, 'some form of market failure must lie at the heart of any concept of public service broadcasting. Beyond simply using the catch-phrase that public service broadcasting must “inform, educate and entertain", we must add “inform, educate and entertain in a way which the private sector, left unregulated, would not do.” Otherwise, why not leave matters entirely to the private sector?' (Davies 1999, p.10).

${ }^{12}$ As described in the Federalist Papers and by writers such as Alexis de Tocqueville and John Stuart Mill. 
${ }^{13}$ Waldfogel (2007, p.22) gives the example of peanut allergy sufferers: around $1 \%$ of the US (and UK) population is allergic to peanuts and consuming even a tiny amount of peanut can be life-threatening for these individuals, yet in some food categories it is difficult to find any products that are entirely peanut-free.

${ }^{14}$ Preference externalities in media markets are analysed in detail by Anderson and Waldfogel (2015).

${ }^{15}$ Surveys can be found in Armstrong and Weeds (2007) and Anderson and Waldfogel (2015).

16 The economics of superstars is analysed by Rosen (1981).

${ }^{17}$ This 'endogenous fixed costs' story is discussed at length in Sutton (1991).

${ }^{18}$ Empirical studies spanning a variety of media markets, surveyed by Anderson and Waldfogel (2015), find higher-cost, higher-quality products in larger markets, providing evidence of endogenous fixed costs.

${ }^{19}$ A summary of empirical findings on demand shifts with digitisation is given in Farchy et al. (2013).

${ }^{20}$ Interestingly, news coverage was not high on the agenda of the early BBC as its Director General, John Reith, wished to avoid treading on the toes of the newspaper barons. The BBC's reputation for timely and reliable news coverage was built during World War II, when it also established its political independence.

${ }^{21}$ Institutional structures are important in this regard. In Germany, for example, an independent auditing commission (Kommission zur Ermittlung des Finanzbedarfs der Rundfunkanstalten, KEF) reports on the funding needs of public service broadcasters and makes a recommendation to state governments.

${ }^{22}$ This concern has recently been highlighted by Peter Oborne in his criticism of The Telegraph's coverage - or lack of it - of adverse news stories concerning banking group HSBC, a major advertiser in the newspaper (Oborne 2015).

${ }^{23}$ A similar problem faces advertisers, who also struggle to gain viewer attention for their adverts and their message across in today's media environment.

${ }^{24}$ Radio soap The Archers, conceived in the 1950s as a means of promoting good farming practice to increase food production, was an early example of this method.

${ }^{25}$ According to the DCMS TV Licence Fee Enforcement Review led by David Perry QC, published in July 2015, in 2013 there were 178,332 prosecutions for failure to hold a TV licence, representing 11.5\% of cases before the Magistrates' Court (DCMS 2015b, p. 10). However, this is likely to overstate the proportion of court costs as cases are typically dealt with very quickly, with most defendants making a written plea of guilty and very few appearing in court. The review also reports that in 201332 people were imprisoned for non-payment of a fine imposed for licence fee evasion (2015b, p. 85).

${ }^{26}$ TV Licensing, which is responsible for collection, estimates that evasion amounted to around 5-6\% of households in 2014-15, costing the BBC between $£ 195 \mathrm{~m}$ and £234m in lost revenue (TV Licensing 2015).

${ }^{27}$ In February 2015 the House of Commons Culture, Media and Sport Select Committee report, Future of the $B B C$ (2015, p. 122) put forward its view 'that criminal penalties for the non-payment of the licence fee and the way enforcement is carried out is anachronistic and out of proportion with the responses to non-payment for other services' but acknowledged 'the possibility [...] that decriminalisation could lead to an increase in evasion and potentially, therefore, a reduction in the BBC's income.' 